\title{
DIRETRIZES PARA PENSAR A MIDIATIZAÇÃO DOS RITUAIS DE CONSUMO NAS TELENOVELAS BRASILEIRAS
}

\author{
Guidelines to think the mediatization of consumption rituals in Brazilian \\ telenovelas
}

\section{Directrices para pensar la mediatización de los rituales de consumo en las telenovelas brasileñas}

\author{
Rosana Mauro $^{1}$ \\ Eneus Trindade ${ }^{2}$
}

\begin{abstract}
Resumo
O artigo busca contextualizar a telenovela nos estudos que abordam a midiatização, de modo geral, e, mais especificamente, a midiatização do consumo. O objetivo é trazer possíveis desdobramentos de pesquisa sobre o assunto pela perspectiva da representação dos rituais cotidianos de consumo nas telenovelas. Pretende-se discutir, brevemente, estudos que trazem novos horizontes de pesquisa na área, como o do pesquisador Andreas Hepp (2014), e suas possíveis aplicabilidades na telenovela brasileira.
\end{abstract}

Palavras-chave: telenovela, midiatização, consumo, rituais de consumo, mídia.

\begin{abstract}
This paper aims to contextualize the telenovela in studies about the mediatization, in general, and more specifically, the mediatization of consumption. The intent is to bring possible research developments about the subject by the perspective of representation of the daily rituals of consumption in telenovelas. We intend to discuss, briefly, studies that bring new research horizons in the area, as the research of Andreas Hepp (2014), and its possible applicability in the Brazilian telenovelas.
\end{abstract}

\footnotetext{
${ }^{1}$ Doutoranda em Ciências da Comunicação pela ECA/USP. Mestre em Ciências da Comunicação pela ECA/USP (2014). Especialista em Comunicação Organizacional - Relações Públicas pela Faculdade Cásper Líbero (2007). Graduada em Jornalismo pela Universidade Metodista de São Paulo (2005). Email: mauro.rosana@gmail.com.

${ }^{2}$ Professor Livre Docente do Departamento de Relações Públicas, Propaganda e Turismo da ECA/USP. Possui pós-doutorado em Antropologia Visual pela Universidade Aberta de Portugal. Doutor e Mestre em Comunicação pela ECA/USP. Docente do PPGCOM/ECA/USP na área de teoria e pesquisa em comunicação e Vice-coordenador do Grupos de Estudos Semióticos em Comunicação, Cultura e Consumo CNPq/ECA/USP. E-mail: eneustrindade@usp.br
} 
Diretrizes para pensar a midiatização dos rituais de consumo nas telenovelas brasileiras de Rosana Mauro e Eneus Trindade

Keywords: telenovela, mediatization, consumption, consumption rituals, media.

\section{Resumen}

El artículo pretende contextualizar los estudios de telenovelas que tratan de la mediatización, en general, y más específicamente, la mediatización de consumo. El objetivo es traer posibles desarrollos de investigación a través de la perspectiva de la representación de los rituales cotidianos de consumo en las telenovelas. La intención es discutir, brevemente, los estudios que traen nuevos horizontes de investigación sobre el tema, como Andreas Hepp (2014), y su posible aplicación en la telenovela brasileña.

Palabras-clave: telenovelas, mediatización, rituales de consumo, medios.

\section{INTRODUÇÃO}

O termo midiatização tem sido bastante discutido em estudos acadêmicos recentemente. $\mathrm{O}$ conceito surgiu como uma forma de abarcar a centralidade cada vez maior da mídia na sociedade e em seus processos (COULDRY \& HEPP, 2013). Há teóricos que o comparam ao termo mais "antigo" mediação, abordam as diferenças entre os dois e também a complementaridade de ambos, como demonstra Trindade e Perez (2014).

É possível apontar, de forma simplificada, como uma das diferenças entre mediação e midiatização, a carga de mudança que o último termo carrega. Conforme pontuam Couldry e Hepp: "Midiatização reflete como as consequências globais de múltiplos processos de mediação têm mudado com a emergência de diferentes tipos de mídia.” (2013:197).

Stig Hjarvard (2014), por sua vez, traz uma perspectiva de midiatização, que nas palavras do próprio autor, se assemelha em determinados pontos com a noção de mediação de Martín-Barbero (2009), no que se refere ao papel da mídia na interação social e mudança cultural. Porém, a midiatização, segundo Hjarvard, aponta para algo adicional: “[...] que as mídias, como estruturas, ou seja, práticas institucionalizadas, conseguiram impulso próprio, o que cada vez mais influencia outras esferas sociais." (HJARVARD, 2014: 26).

De acordo com Couldry e Hepp (2013: 197), de modo amplo, é possível definir midiatização como "[...] um conceito usado para analisar criticamente a inter-relação 
Diretrizes para pensar a midiatização dos rituais de consumo nas telenovelas brasileiras de Rosana Mauro e Eneus Trindade

entre mudanças na mídia e comunicações por um lado, e mudanças na cultura e sociedade, por outro".

Sugerimos aqui que o conceito de midiatização é pertinente para as discussões teóricas sobre a telenovela, uma vez que ela apresenta um papel privilegiado na construção de um imaginário social brasileiro e influencia diversos processos sociais, dentre eles o consumo.

De acordo com Lopes (2009), a telenovela é uma figura central da cultura e da identidade do Brasil e é o produto de maior popularidade e lucratividade da televisão brasileira, além de colocar no cotidiano discussões sociais importantes, como o casamento inter-racial, problemas de violência, dificuldades enfrentadas por portadores de necessidades especiais, bulimia juvenil, etc. Ademais, o folhetim eletrônico se apropria do cotidiano e toma forma de memória histórica da sociedade brasileira (MOTTER, 2000-2001).

Outro trabalho de Lopes (2004) traz um importante estudo sobre a globalização e suas ambivalências na narrativa televisiva. Para a autora, a telenovela possui um valor estratégico na criação e consolidação de novas identidades culturais, já que ela possui o caráter de narrativa popular sobre a nação e configura-se como o local onde a nação é representada e imaginada (LOPES, 2004: 121). .

Porém, antes de adentrarmos na telenovela especificamente, é importante expor, de maneira breve, as diferentes vertentes de pesquisa e visões sobre a midiatização para tentar traçar, assim, possíveis aplicabilidades para o objeto aqui discutido.

\section{MIDIATIZAÇÃO E MIDIATIZAÇÃO DO CONSUMO}

As teorias e trabalhos disponíveis sobre a midiatização indicam que não há uma forma única de se olhar para a problemática e nem um conceito unânime sobre a questão. De acordo com Couldry e Hepp (2013: 197), alguns pesquisadores entendem a midiatização como um processo longo que tem acompanhado toda a história da humanidade; enquanto outros usam o termo para descrever o crescimento da relevância social e cultural da mídia desde a emergência da mídia de massa, como a imprensa, o rádio, o cinema e a televisão.

Ademais, Couldry e Hepp (2013) e Hepp (2014) identificam duas correntes de estudo sobre a midiatização: a institucionalista e a tradição socioconstrutivista. Elas coexistem e estão se tornando cada vez mais convergentes recentemente. 
Diretrizes para pensar a midiatização dos rituais de consumo nas telenovelas brasileiras de Rosana Mauro e Eneus Trindade

Segundo Hepp (2014: 47), a tradição institucional tem se interassado mais pela mídia tradicional de massa, cuja influência é descrita como lógica de mídia; enquanto a tradição socioconstrutivista se concentra, sobretudo, nas práticas de comunicação cotidianas relacionadas, principalmente, à mídia digital, além de focar na construção comunicativa em transformação da cultura e da sociedade.

A tradição institucionalista enxerga a mídia como uma instituição mais ou menos independente com uma lógica própria. A midiatização seria, assim, uma adaptação de diferentes campos sociais às regras midiáticas institucionalizadas. Já a vertente socioconstrutivista enfatiza a complexidade da mídia como instituição e tecnologia, entendendo a midiatização de forma mais aberta, como um processo de construção comunicativa da realidade (COULDRY \& HEPP, 2013: 196-197).

Mas, como ambas as vertentes estão abertas uma à outra, Hepp argumenta que:

Por um lado, os expoentes da tradição institucionalista estão repensando o conceito de lógica da mídia; por outro lado, expoentes da tradição socioconstrutivista enfatizam a necessidade de também investigar a dimensão institucional da midiatização. (HEPP, 2014: 49-50).

Stig Hjarvard (2014) - que segundo palavras de Hepp (2014: 48) foi quem trouxe a perspectiva institucional para o discurso da midiatização - argumenta que nos últimos cem anos, os meios de comunicação se tornaram uma instituição separada da sociedade e a mídia se tornou onipresente. Além disso, o autor expõe que a midiatização sob sua perspectiva deve ser entendida como um processo da alta modernidade, “[...] na qual os meios de comunicação não só estão sujeitos às principais transformações da sociedade moderna, mas são eles próprios agentes de modernização [...]” (HJARVARD, 2014: $31)$.

Contrariamente a essa posição, o pesquisador Eliseo Verón (2014: 15-16) acredita que a midiatização é o resultado da capacidade humana de semiose, que pode se expressar em fenômenos midiáticos. E estes são uma característica universal de todas as sociedades humanas. $\mathrm{O}$ autor explica que a midiatização é um nome para a longa sequência histórica de fenômenos midiáticos sendo institucionalizados e que o que está acontecendo nas sociedades da modernidade tardia começou há muito tempo.

O pesquisador brasileiro José Luiz Braga (2006: 04), por sua vez, faz parte da tradição socioconstrutivista e acredita que estamos vivendo uma transição entre um processo interacional de referência da escrita para um processo interacional de referência midiatizado de base tecnológica. Um processo interacional de referência se 
Diretrizes para pensar a midiatização dos rituais de consumo nas telenovelas brasileiras de Rosana Mauro e Eneus Trindade

refere não só à hegemonia e preferência por um modo de interação (o escrito, por exemplo), mas também considera que a sociedade é organizada através desse modo interativo (BRAGA, 2006: 03).

De acordo com o autor, a midiatização pode ser relacionada a processos específicos que passam a se desenvolver de acordo com a mídia, como a política, e também pode estar relacionada a um nível maior, no sentido da própria sociedade estar midiatizada (BRAGA, 2006: 01). De acordo com as explicações do teórico, é possível considerar o consumo como um processo específico que passa a se desenvolver de acordo com a mídia.

A concepção de Braga é proveitosa para o nosso ponto de vista uma vez que ela não relaciona a midiatização apenas com a alta modernidade e sim a descreve como um processo de longo prazo. Mas, diferente de Verón (2014), Braga (2006) pontua o movimento de transformação pelo qual estamos passando, em direção a um modo interacional de referência de base tecnológica. Desse modo, as mudanças sociais mais recentes configuram momentos importantes para a midiatização, com o advento de novas tecnologias e formas de comunicação, por exemplo.

Outra abordagem pertinente de ser exposta, que revela um caráter promissor para o estudo da midiatização do consumo, é a trazida por Hjarvard (2012: 66) sobre uma midiatização direta e outra indireta. A direta é quando uma determinada atividade passa a ser executada de uma forma diferente devido à mídia, como, por exemplo, jogar xadrez ou fazer transações bancárias pela internet. A forma indireta se refere à influência cada vez maior da mídia em uma determinada atividade, mas que não afeta diretamente o modo como as pessoas executam uma tarefa; trata-se de uma influência mais sutil, como, por exemplo, o conhecimento que os brasileiros possuem acerca dos Estados Unidos, o qual é formado em partes pelos meios de comunicação (HJARVARD, 2012: 67).

É possível sugerir que a midiatização do consumo ocorra tanto de forma direta quanto indireta. No primeiro caso, as compras online seriam um exemplo; já a forma indireta pode se referir ao modo como a mídia está presente, subjetivamente, a todo o momento nos processos de compra e nos rituais de consumo das pessoas. Também no âmbito da midiatização indireta podemos inserir a telenovela que, junto com a publicidade e outros formatos de comunicação e mídias, propaga modos de consumir por meio dos rituais de consumo de seus personagens. 
Diretrizes para pensar a midiatização dos rituais de consumo nas telenovelas brasileiras de Rosana Mauro e Eneus Trindade

O trabalho realizado pelos pesquisadores Eneus Trindade e Clotilde Perez (2014) traz contribuições importantes sobre a midiatização no consumo. Os autores fazem uma abordagem conceitual que reflete sobre as dimensões teóricas da presença da mídia na formação de hábitos e atitudes de consumo e na construção de vínculos de sentidos entre as expressões da marca/produtos/serviços e seus consumidores (2014: $01)$.

De acordo com os autores, os estudos da área não têm discutido a presença midiática do consumo na perspectiva tratada por eles no artigo. O que tem sido feito, pelo menos no Brasil, é abordar o consumo midiático, que se aproxima mais dos estudos de recepção, enquanto os estudos do consumo midiatizado “[...] buscam compreender as formas de presença e consequências das atuações do sistema publicitário (via marcas de empresas, produtos e serviços)" (TRINDADE \& PEREZ, 2014: 03).

Trindade e Perez (2014) explicam que a comunicação de marcas por meio do sistema publicitário gera práticas referencias culturais de consumo. Desse modo, o ritual de consumo do ponto de vista comunicacional é percebido "[...] como dispositivo articulador dos sentidos dos produtos/marcas na vida das pessoas, portanto, a presença do sistema publicitário é constitutiva nesta relação de consumo.” (TRINDADE \& PEREZ, 2014: 05).

Em outro trabalho, Trindade e Perez (2013) exibem perspectiva semelhante, mas com mais explicações teóricas sobre o termo ritual. O texto traz a contribuição de diversos autores sobre o tema e propõe que a questão do ritual na sociedade contemporânea exige posturas que não estejam presas apenas ao viés antropológico, mas que considerem também características da vida social atual (TRINDADE \& PEREZ, 2013: 05). Neste contexto, os autores abordam os estudos do antropólogo Grant McCracken (2003), de acordo com o qual, o significado do mundo culturalmente constituído é transportado para os bens mediante o sistema publicitário e da moda. Os indivíduos, por sua vez, transferem o significado dos bens para suas vidas, pelos rituais de posse e também pelos rituais de troca, arrumação e despojamento.

A partir disso, Trindade e Perez propõem um vasto campo de investigação sobre os rituais de consumo.

É a partir disso que surge a nossa percepção para a constituição de um vasto campo de investigação sobre os rituais de consumo nos vários setores da vida cultural material, pois cada setor dependendo da sua finalidade social em seus rituais de compra, posse, vários tipos de usos e formas de descartes ou transformações, ganha gradientes de 
Diretrizes para pensar a midiatização dos rituais de consumo nas telenovelas brasileiras de Rosana Mauro e Eneus Trindade

sentidos e formas de vinculações e desvinculações em seus respectivos contextos de interações entre suas marcas e consumidores. (TRINDADE \& PEREZ, 2013: 7).

Trindade e Perez (2013) apresentam uma concepção de rituais de consumo de cunho transdisciplinar, que atenda tanto a dimensão antropológica quanto a dimensão comunicacional. Para os autores, do ponto de vista comunicacional, que é o que nos interessa neste artigo, conforme abordado anteriormente, o ritual de consumo é percebido como um dispositivo articulador e mediador de sentido dos produtos e marcas na vida das pessoas, "[...] a presença do sistema publicitário é constitutiva nesta relação de consumo" (TRINDADE \& PEREZ, 2013: 9).

Os pesquisadores destacam dois pontos de partida para a investigação desses dispositivos como caminhos para a compreensão da midiatização da comunicação publicitária na sociedade de consumo. O primeiro seria os rituais de consumo representados nas manifestações do sistema publicitário, a midiatização dos rituais de consumo; e o outro se refere aos rituais de consumo em si, a mediação cultural dos rituais de consumo.

É possível trazer esses pontos de partida para o caso da telenovela, considerando- a como parte do sistema publicitário. Uma pesquisa nesse âmbito pode contemplar tanto as representações dos rituais do consumo nas tramas, como a presença da telenovela e seus rituais ficcionais nos rituais de consumo reais das pessoas. É plausível versar sobre os rituais de consumo como dispositivos entre os personagens e os produtos/marcas na ficção, ou enquanto dispositivos na realidade entre pessoas e produtos/marcas, na qual a telenovela, junto de outros formatos e mídias, se faz presente, supomos, de modo indireto conforme a midiatização indireta teorizada por Hjarvard (2012).

Contudo, de outro modo, a telenovela pode ela própria ser qualificada, dentro da midiatização do consumo, um dispositivo ${ }^{3}$ midiático com poder de influenciar outras mídias e a própria publicidade tradicional, por meio da representação de rituais cotidianos de consumo de seus personagens.

$\mathrm{Na}$ verdade, a influência comercial das telenovelas brasileiras já faz parte de um conhecimento comum. Cabe aos estudos de comunicação pesquisar como esse potencial se dá e qual os seus desdobramentos. Destacamos neste processo a importância do

\footnotetext{
${ }^{3}$ A palavra dispositivo é empregada aqui do modo teorizado por Trindade e Perez (2013) que utilizam os conceitos de Foucault (2012) e Agamben (2010).
} 
Diretrizes para pensar a midiatização dos rituais de consumo nas telenovelas brasileiras de Rosana Mauro e Eneus Trindade

cotidiano ficcional e da representação dos rituais de consumo. Para tanto, discutiremos a seguir algumas características comerciais da telenovela que nos levam a esse caminho.

\section{TELENOVELA E COTIDIANO FICCIONAL}

É importante destacar, nesse panorama, as especificidades da telenovela brasileira que a torna conectada com a realidade nacional e seu consumo. A teleficção nacional diferenciou-se, ao longo do tempo, das produções realizadas em outros países da América Latina, devido à sua carga de realismo. A pesquisadora Cristina Mungioli (2010:60) aponta que no final da década de 1960 os autores brasileiros começaram a tratar de temas sociais nas tramas e a mostrar o cotidiano de diferentes classes sociais.

Assim, uma definição clara no tempo e no espaço possibilitou à telenovela situar-se cada vez mais no contexto nacional, o que potencializou seu caráter comercial (HAMBURGER, 1998: 467).

Conforme pontua a estudiosa Heloisa Buarque de Almeida (2003: 163), a telenovela pode ser uma vitrine de produtos e de estilos de vida associados aos bens de consumo. As tramas televisuais mostram como as personagens se vestem, se comportam e consomem bens e serviços, o que significa uma oportunidade rentável para empresas e marcas.

Temos, então, que a representação dos rituais cotidianos de consumo é relevante nessa dinâmica. Independente das ações de merchandising, os personagens de telenovela são representados constantemente em situações cotidianas que remetem ao consumo, o que contribui para a construção de uma realidade ficcional que passa a se relacionar também com o cotidiano fora da telenovela, como exprime a estudiosa Maria Lourdes Motter (2003).

Em seu trabalho, realizado com telenovelas veiculadas entre 1995 e 1997, Motter afirma haver uma afinidade entre sua formação teórica e as pesquisas ligadas à sociologia do conhecimento, no que diz respeito à importância e o papel dos processos simbólicos e comunicativos "[...] como pressupostos da sociabilidade, na perspectiva dos processos de construção da realidade" (MOTTER, 2003: 129). Embora, a autora não usasse o termo midiatização, é plausível identificar em sua colocação preocupação similar àquela que o conceito de midiatização e seus teóricos trazem para os estudos de comunicação atualmente. 
Diretrizes para pensar a midiatização dos rituais de consumo nas telenovelas brasileiras de Rosana Mauro e Eneus Trindade

Motter se preocupa em demonstrar como a ficção televisiva pauta a grande imprensa informativa com temas sociais e discussões de interesse público. De acordo com essa posição, a estudiosa (2003: 32) chama a atenção para a importância da instituição de um cotidiano nas telenovelas que acaba por se relacionar com a realidade fora delas. O cotidiano da teleficção, segundo a estudiosa, prende os personagens no tempo e no espaço, e traz, assim, realidade à trama.

Dentre outros elementos, o cenário permite a construção dessa cotidianidade. A permanência do mesmo cenário confere aos personagens um modo de habitar, de ser, assim como o que eles consomem tem igual função (MOTTER, 2003: 114). Desse modo, a cotidianidade dos personagens é construída em interação com o ambiente.

[...] onde tudo deve "funcionar": cama, fogão, geladeira, etc. Onde a comida seja para comer, o vinho, o café, o leite, para beber. Desse modo marcam-se horas do dia, hábitos, preferências que evidenciam o gosto e o caráter da personagem. É no âmbito da vida doméstica, mas não só, que elas se destacam como "pessoas" que "vivem" um cotidiano em paralelo com o do telespectador. (MOTTER, 2003: 167).

Diante de tais explanações, acredita-se que a cotidianidade na telenovela e seus rituais de consumo, entre outros elementos, possibilitam um vínculo entre ficção e realidade. Os rituais cotidianos trazem vida aos personagens, dizem quem eles são, o que fazem, o que consomem e como consomem, trazem um sentido, inclusive, de classe social à qual o universo da telenovela pretende remeter.

A dissertação de mestrado de Mauro (2014) transparece, em certo sentido, a importância da representação dos rituais cotidianos de consumo na construção de um sentido de classe social nas tramas Avenida Brasil (2012), de João Emanuel Carneiro, e Cheias de Charme (2012), de Filipe Miguez e Izabel de Oliveira. Em Avenida Brasil, principalmente, os rituais de consumo de alimentação, pela representação dos personagens reunidos à mesa, foram relevantes para a construção das características concernentes à classe social da família principal, seus gostos alimentares, modos de se portar, de falar, de usar os talheres, entre outros aspectos que mostram a distinção social, como diria Peirre Bourdieu (2007).

Embora a dissertação de mestrado citada não tenha explorado a presença das telenovelas em outras mídias, é importante expor o trabalho que a Rede Globo vem desempenhando na internet para expandir o sentido de suas tramas e aumentar as possibilidades de diálogo com o telespectador, também no que diz respeito ao consumo, com merchandising ou não. 
Diretrizes para pensar a midiatização dos rituais de consumo nas telenovelas brasileiras de Rosana Mauro e Eneus Trindade

Além disso, existem os formatos que permitem maior interação com o telespectador e internauta, ainda no âmbito da produção, e as iniciativas dos próprios telespectadores na produção de conteúdo vinculado à telenovela. Tudo isso faz parte do novo contexto cultural e midiático de participação e compartilhamento como sinaliza Shirky (2011).

Considerando as novas tecnologias, Trindade e Perez (2014: 6-7) apontam três aspectos que podem nortear um possível corpus empírico do sistema publicitário para a compreensão dos processos de midiatização. $O$ primeiro diz respeito justamente ao alargamento dos formatos, conteúdos e plataformas, que engloba novas ações de participação, colaboração e interação com os consumidores; o segundo diz respeito à percepção de que as tecnologias de comunicação favorecem a interação, participação e colaboração em diversos graus, e esses diferentes graus de interação devem ser mapeados, caso a caso; e o último aspecto se refere ao fato da tecnologia modular o social por uma lógica algorítmica e o poder estar com quem sabe programar.

Ao introduzir a telenovela como parte desse sistema publicitário, é possível trazer um recorte de estudo que a considere dentro dessas três dimensões explicitadas por Trindade e Perez (2014). O primeiro aspecto levantado nos interessa especificamente, pois ele nos remete aos novos formatos e plataformas que dão suporte à teleficção. Estudar a interação entre essas diferentes e novas mídias é uma forma também de renovar uma intenção já trazida pelo estudo de Motter (2003), ao abarcar a capacidade da telenovela gerar temas para a imprensa noticiosa, relacionando o cotidiano ficcional com o cotidiano noticioso.

Contudo, um estudo de midiatização, acredita-se, não deve focar só as novas mídias, mas também a mídia de massa. Uma pesquisa requer, assim, um recorte e um corpus definido, que considere o relacionamento entre determinadas mídias - e atentase também aos diversos formatos e gêneros comunicacionais dentro delas - para a midiatização de dado processo.

Desta forma, os conceitos de forças de moldagem, mundos midiatizados e configurações comunicativas, trazidos por Hepp (2014) são bastante frutíferos para a proposta pretendida.

Hepp utiliza a metáfora forças de moldagem, como uma forma de relacionar as duas tradições da midiatização - a socioconstrutivista e institucionalista. O termo indica que "[...] não podemos presumir um efeito geral ou livre de contexto da mídia específica; entretanto, diferentes mídias moldam a comunicação de formas diversas." 
Diretrizes para pensar a midiatização dos rituais de consumo nas telenovelas brasileiras de Rosana Mauro e Eneus Trindade

(HEPP, 2014: 51). O autor explica que a expressão capta dois processos relacionados à mídia: sua institucionalização e sua reificação, ou seja, a materialização de aspectos sociais, culturais e humanos, que a midiatização representa.

Hepp atenta para o fato de que a história humana não é um processo de mudança de uma mídia a outra, e sim um processo cumulativo que conta com o aumento da institucionalização e reificação de uma variedade de mídias.

"Como consequência, somos confrontados com o fato de que não apenas um meio molda a construção comunicativa da realidade, mas uma variedade de meios diferentes faz isto ao mesmo tempo.” (HEPP, 2014: 53).

Assim, a midiatização é caracterizada pelo fato de vários campos da cultura e da sociedade serem comunicativamente construídos por meio de uma variedade de mídias concomitantemente.

Do mesmo modo, a telenovela conta com diferentes mídias, além de formatos e gêneros comunicativos dentro delas. É possível explorar a midiatização do consumo via representação de rituais de consumo na telenovela junto de outros programas da televisão que dão suporte às tramas, bem como com a publicidade em diferentes mídias, com notícias de jornais e revistas, além das mídias digitais, como de sites, blogs e páginas em redes sociais oficiais de cada telenovela, entre outras formas. Tem-se, assim, um quadro abrangente a ser explorado.

Para descrever a midiatização de forma a capturar essa abrangência das diferentes mídias, Hepp traz o conceito de mundos midiatizados, que podem ser entendidos como pequenos mundos da vida ou mundos sociais, que dependem constitucionalmente de uma articulação pela comunicação midiática. Os mundos midiatizados são, para o autor, o nível no qual a midiatização se torna concreta e pode ser analisada empiricamente (HEPP, 2014: 53). No caso pretendido neste artigo, podemos tratar do mundo midiatizado da telenovela mediante rituais de consumo de forma abrangente ou específica - como o consumo alimentício, de vestuário, cultural, entre outros -, envolvendo outras mídias que se relacionem com a telenovela e contribuam para a produção de sentido do cotidiano ficcional.

Para operacionalizar a pesquisa, outro conceito importante levantado por Hepp é o de configuração. "[...] podemos falar de configurações comunicativas como padrões de processos entrelaçando o que existe ao longo de várias mídias e em um "enquadramento temático" que orienta a ação comunicativa." (HEPP, 2014: 56). É 
Diretrizes para pensar a midiatização dos rituais de consumo nas telenovelas brasileiras de Rosana Mauro e Eneus Trindade

possível, segundo o pesquisador, pesquisar a midiatização mediante a análise das transformações das configurações de comunicação dos mundos midiatizados.

O termo configuração se faz oportuno, pois ele abarca a importância de se olhar para a especificidade de cada mídia no processo de midiatização, e mais que isso oferece a possibilidade de conceber determinadas mídias de forma interconectada em uma situação específica de midiatização. Por meio desse conceito, acreditamos ser possível concentrar-se nos discursos de uma dada configuração comunicativa da telenovela e entender como os diversos rituais de consumo da trama são expandidos e ressignificados em cada mídia.

Desse modo, a forma como Fausto Neto (2010) trata a interdiscursividade e a circulação midiática nos parece pertinente para o objetivo aqui proposto. $\mathrm{O}$ autor versa sobre uma ordem interdiscursiva que transcende o sujeito individual ou institucional da onde parte o ato comunicativo, sugerindo que a emissão comunicativa também é efeito de uma atividade discursiva e não "mestre". "[...] Trata-se da ordem interdiscursiva onde a circulação - como "terceiro" - se oferece como um novo lugar de produção, funcionamento e regulação de sentidos." (FAUSTO NETO, 2010: 60).

A concepção de circulação mostra-se conveniente para os estudos de midiatização nos parâmetros expostos anteriormente. Pois, ao invés de separar emissão e recepção como duas instâncias com contornos claros, essa visão de uma zona comunicativa de articulação entre produção e recepção (FAUSTO NETO, 2010) parecenos capaz de tratar a midiatização de forma condizente com o novo cenário sóciotécnico-discursivo em que vivemos (2010: 59) e com a concepção de configurações comunicativas, nas quais, supõe-se, ser possível investigar sinais dessa zona de articulação sem a necessidade de tratar a recepção de maneira isolada da produção/emissão.

Isto posto, acreditamos na viabilidade de analisar o "mundo midiatizado" da telenovela, por meio do recorte dos seus rituais de consumo e sua conexão com a realidade, contemplando o discurso de uma configuração comunicativa determinada, de modo a abranger os vestígios da circulação nos discursos midiáticos envolvidos, ou seja, indícios das zonas de contato entre produção e recepção. Supomos que tal escopo de investigação possa proporcionar uma pequena contribuição para as pesquisas de comunicação no âmbito da midiatização do consumo.

\section{CONSIDERAÇÕES FINAIS}


Diretrizes para pensar a midiatização dos rituais de consumo nas telenovelas brasileiras

Este artigo procurou, de maneira breve, trazer possíveis caminhos de pesquisa no contexto da telenovela e da midiatização do consumo. Trouxemos resumidamente algumas explanações sobre o conceito de midiatização e, mais especificamente, a midiatização do consumo a fim de situar a telenovela dentro desta discussão.

Com o aporte dos argumentos de Trindade e Perez (2013/2014), focamos na possibilidade de pesquisar a telenovela, enquanto um dispositivo midiático, a partir das representações dos rituais de consumo nas tramas, na construção de um cotidiano ficcional que dialoga com a realidade (MOTTER, 2003) e que, com a articulação de outras mídias, insere-se no panorama da midiatização do consumo.

De acordo com a complexidade do tema, são muitos os caminhos e recortes viáveis. Por isso, acredita-se que os conceitos de Hepp (2014) de forças de moldagem, mundos midiatizados e configurações comunicativas possam trazer operacionalidade a pesquisas sobre o tema.

O artigo indica, por fim, um possível caminho de investigação, que considere o enfoque discursivo de determinadas configurações comunicativas em torno da telenovela e a representação de rituais de consumo, sob a luz do conceito de circulação (FAUSTO NETO, 2010) e do princípio da interdiscursividade dentro de um processo de midiatização do consumo. Trata-se, contudo, de uma ideia bastante inicial que carece de aprofundamentos e ajustes, mas cujas diretrizes foram aqui apresentadas e postas em discussão.

\section{REFERÊNCIAS BIBLIOGRÁFICAS}

ALMEIDA, H. B. de. Telenovela, Consumo e Gênero. Bauru, SP: EDUSP, 2003.

AGAMBEN, G. O que é o contemporâneo? E outros ensaios. Chapecó: Argos, 2010.

BOURDIEU, P. A Distinção: crítica social do julgamento. Tradução: Daniela Kern; Guilherme F. Teixeira. São Paulo: Edusp; Porto Alegre: Zouk, 2007.

BRAGA, J. L. "Sobre mediatização como processo interacional de referência", In Encontro Anual da Associação Nacional dos Programas de Pós-graduação em Comunicação - Compós, 2006, Bauru SP. Anais XV Compós Encontro Anual da Associação Nacional dos Programas de Pós-Graduação em Comunicação. Bauru, SP: Compós, 2006: 16. 
Diretrizes para pensar a midiatização dos rituais de consumo nas telenovelas brasileiras de Rosana Mauro e Eneus Trindade

COULDRY, N \& HEPP, A. "Conceptualizing mediatization: contexts, traditions, arguments", In Communication Theory, vol. 23, Issue 3, 2013: 191-201.

FAUSTO NETO, A. "Nas Bordas da circulação", In Revista Alceu, no 20, vol. 10, Rio de Janeiro, 2010: 55-69.

FOUCAULT, M. Microfísica do Poder. São Paulo: GRAAL, 2012.

HAMBURGER, E. "Diluindo fronteiras: a televisão e as novelas no cotidiano", In SCHWARCZ, L. M. (org.) História da Vida Privada no Brasil. São Paulo: Companhia das Letras, 1998.

HEPP, A. "As configurações comunicativas de mundos midiatizados: pesquisa da midiatização na era da "mediação de tudo"”, In Matrizes, no 1, vol. 8, São Paulo, 2014: 21-44.

HJARVARD, S. "Midiatização: conceituando a mudança social e cultural”, In Matrizes, no 1, vol. 8, São Paulo, 2014: 21-44.

HJARVARD, S. "Midiatização: teorizando a mídia como agente de mudança social e cultural”, In Matrizes, $\mathrm{n}^{\circ}$ 2, vol. 5, São Paulo, 2012: 53-92.

LOPES, M. I. V. de. "Para uma revisão das identidades coletivas em tempo de globalização”, In LOPES, M. I. V. de (org.). Telenovela: internacionalização e interculturalidade. São Paulo: Loyola, 2004.

LOPES, M. I. V. de. "Telenovela como recurso comunicativo", In Matrizes, $\mathrm{n}^{\circ}$ 1, vol. 3, São Paulo, 2009: 21-47.

MARTIN-BARBERO, J. Dos meios às mediações. Comunicação, cultura e hegemonia. Tradução: Ronald Polito e Sérgio Alcides. Rio de Janeiro: Editora UFRJ, 2009.

MAURO, R. Aspectos da midiatização do consumo e do sentido de classe social na telenovela: a representação da "nova classe C". Dissertação de Mestrado. São Paulo: ECA - USP, 2014: 159

MCCRACKEN, G. Cultura \& Consumo. Tradução: Fernanda Eugenio. Rio de Janeiro: Mauad, 2003.

MOTTER, M. L. "A telenovela: documento histórico e lugar de memória”, In Revista USP, $\mathrm{n}^{\circ}$ 48, São Paulo, 2000-2001:74-87.

MOTTER, M. L.. Ficção e Realidade: A construção do cotidiano na telenovela. São Paulo: Alexa Cultural, Comunicação \& Cultura - Ficção Televisiva, 2003.

MUNGIOLI, M. C. P.. "Ecos da memória da nação na Minissérie Queridos Amigos”, In Comunicare, $\mathrm{n}^{\mathrm{o}}$ 2, vol.10, São Paulo, 2010: 54-69.

SHIRKY, C. A cultura da participação. Rio de Janeiro: Zahar, 2011. 
Diretrizes para pensar a midiatização dos rituais de consumo nas telenovelas brasileiras de Rosana Mauro e Eneus Trindade

TRINDADE, E. "Mediações e Midiatizações do Consumo", In Congresso Brasileiro de Ciências da Comunicação - INTERCOM, 2014, Foz do Iguaçu. Anais XXXVII Congresso Brasileiro de Ciências da Comunicação. Foz do Iguaçu: Unicentro/Unila/UDC/Fundação PTI. 2014: 15.

TRINDADE, E. \& PEREZ, C.. “Dimensões do consumo midiatizado”, In II Congresso Mundial de Comunicação Ibero-Americana - CONFIBERCOM, 2014, Braga. Anais II Confibercom. Braga: Universidade do Minho, 2014: 9.

TRINDADE, E. \& PEREZ, C. "Rituais de Consumo: dispositivos midiáticos de articulação de vínculos de sentidos entre marcas e consumidores", In IX Seminário Internacional Imagem da Cultura. Cultura das Imagens, 2013, São Paulo. Anais IX Seminário Internacional Imagem da Cultura. Cultura das Imagens. São Paulo: ECA/USP, 2013: 12.

VERÓN, E. "Teoria da midiatização: uma perspectiva semioantropológica e algumas de suas consequências", In Matrizes, nº 1, vol. 8, São Paulo, 2014: 13-19.

Artigo submetido: 03/11/2014

Artigo aprovado: 25/11/2014 